\title{
Beyond COVID-19: the future of maritime transport
}

\author{
Laura Carballo Piñeiro ${ }^{1}$ Maximo Q. Mejia Jr ${ }^{1} \cdot$ Fabio Ballini $^{1}$
}

Published online: 31 May 2021

C) World Maritime University 2021

\section{Introduction}

On March 11, 2020, the World Health Organization (WHO) declared the COVID-19 disease a pandemic and, since then, the health crisis rapidly developed into a social, political, and economic one across the globe. As indicated by the UN Conference on Trade and Development (UNCTAD), and in order to overcome these devastating effects that seriously threaten the achievement of the UN Sustainable Development Goals (SDG), we need to ensure uninterrupted shipping (UNCTAD 2020a).

Shipping is the backbone of international trade. Carrying more than $80 \%$ of cargo by volume and $70 \%$ by value, it is the most efficient mode of transportation. The global ports sector handles similar dimensions, moving over $80 \%$ of global merchandise trade in volume and more than two-thirds of its value (UNCTAD 2019). In this context, port performance is a key indicator of trade efficiency that determines connectivity and trade costs (Micco et al. 2003). Measuring the impact of COVID-19, the WPSP-IAPH COVID19 Port Economic Impact Barometer reported in 2020 a pendulum swing from over-capacity to under-utilization at some port storage areas, highlighting that Latin American ports were impacted by hinterland delays, dock worker shortages, and truck driver availability more than in other global regions (IAPH-WPSP Port Economic Impact Barometer 2020). In 2021, the situation remains uncertain, although it cannot be denied that COVID-19 has had a huge global economic impact that negatively affected the mismatch between supply and demand, among other issues. More specifically, the human element in maritime safety is an issue of major concern while other matters are moving forward, in particular the maritime environmental policy agenda, the accelerated pace towards digitization, and shipping and port business models.

In June 2020, the WMU Journal of Maritime Affairs launched a Special Call for Papers with a view to attracting discussion on a variety of issues and topics from the perspectives of how to restore, enhance, and adjust the existing maritime legal framework to the situation created by the pandemic, how political approaches to global trade and business models are evolving in view of the challenges posed by COVID-19, and

Laura Carballo Piñeiro

lc@wmu.se

1 World Maritime University, Malmö, Sweden 
how the UN SDGs can be advanced under the prevailing uncertain scenario. Fifty-four authors responded and submitted 17 papers covering some of the questions raised by the Call. Four of them addressed the human element from the perspective of maritime education and training; two covered the maritime environmental policy agenda dealing with ship energy efficiency and decarbonization, as well as with the EU legal framework to address an environmental sustainable shipping; another two discussed cybersecurity from different angles; and the remaining nine focused on the socio-economic impact of the COVID-19 pandemic in shipping and ports from a variety of perspectives and regional locations around the world. The WMU Journal of Maritime Affairs has been privileged to receive seventeen submissions, but through the usual reviewing processes, only six have been accepted for publication in this Special Issue. We wish to take this opportunity to thank all reviewers engaged in assessing the papers for their commitment and constructive criticism.

\section{The human element in maritime safety}

The COVID-19 pandemic has threatened to change the approach to safety in a disruptive manner reminiscent of the effects the 9/11 attacks had on the maritime security regime. Travel restrictions to combat COVID-19 have put a halt on basic human and labour rights that have led to different reactions - from a Declaration by the Port Authorities Roundtable (PAR) on the global COVID-19 situation (IMO 2020a), to guidance on protection of health, repatriation, and travel arrangements for seafarers, passengers, and other persons on board ships (European Commission 2020; IMO 2020b; IMO-ICAO-ILO 2020). One year later, and although the number of seafarers unable to be repatriated has diminished, the difficulties in successfully completing crew changes continue and with them, pressing occupational safety and health matters that flag States, port States, and labour-supplying countries have still not managed to address. The ILO Special Tripartite Committee (STC) of the Maritime Labour Convention, 2006 (MLC, 2006), finalised its fourth meeting held from 19 to 23 April 2021 with a Resolution (Special Tripartite Committee of the MLC, 2006 2021) that starts with a reminder to ratifying States of their obligations in accordance with Articles I(2), III, and V(6) of the MLC, 2006, in particular to cooperate with each other for the purpose of ensuring the effective implementation and enforcement of the Convention, to respect the fundamental rights and principles, and to prohibit violations of the requirements of the Convention.

The STC Resolution signals the need for additional measures to the existing international legal framework that has been suspended without taking into consideration less invasive measures, particularly the key role that seafarers and other maritime professionals play in the global supply chain. Remarkably, the WHO International Health Regulations 2005 (IHR 2005) provide for measures “ ...to prevent, protect against, control and provide a public response to the international spread of disease in ways that are commensurate with and restricted to public health risks, and which avoid unnecessary interference with international traffic and trade" (See Article 2 of IHR 2005), including the obligation to safeguard travelers against overly burdensome interferences in their freedom, as well in trade of goods (See Part V of IHR 2005). As a matter of fact, these provisions have been drafted taking into consideration past 
experiences and the need to balance the right to health against other human rights, including freedom of movement. Already in 1851, and as a result of a pandemic caused by cholera, several European countries attended a conference in Paris to create a common framework for harmonizing response as a result of measures restricting maritime transportation, in particular at the moment of arriving into foreign ports. However, the IHR 2005 are secondary law and each State is responsible for their implementation. Lack of cooperation is a major issue that the intensive work of the UN agencies cannot fully overcome, a painful lesson learned by shipping these past months. Against this backdrop, a proposal has been made to further dig into these rules and move towards an international treaty on pandemic prevention and preparedness (Council of the European Union 2021; von Bogdandy \& Villarreal 2020).

The same applies to the MLC, 2006, whose rules have been seriously challenged by the measures adopted to fight against the COVID-19 pandemic. The question is now whether and how these rules can be enhanced to ensure seafarers' rights as the ongoing discussion before the STC reveals. The downside of this approach is that social dialogue seems to be just focused on solving the appalling breaches of the MLC, 2006, but not on solving other major issues that the convention itself has not managed to properly addressed, in particular the underreporting of hours of work/rest-as illustrated in a WMU report (World Maritime University 2020) - and the increase in salaries as illustrated by the lack of agreement on a minimum wage by the Joint Maritime Commission.

On a positive note, the adoption of digital technologies in various aspects of maritime operations has helped to support seafarers' rights, including facilitating qualifications to get a job. "The Continuum of Maritime Simulator-based Training and Education" by Tae-eun Kim, Amit Sharma, Morten Bustgaard, William C Gyldensten, Ole Kristian Nymoen, Hasan Mahbub Tusher, and Salman Nazir, published in this issue, examines the role of existing simulators in Maritime Education and Training (MET) and how they can advance the latter by resorting to virtual reality and cloud-based simulators. Simulators are key to seafarers' training and competences, and more so in a world where travel and gatherings have been restricted. However, changing to an online environment might bring changes as examined in this paper, in particular as regards to training practices and the role of instructors, including assessment exercises. Inga Bartuseviciene, Anne Pazaver, and Momoko Kitada discuss similar challenges in their paper "Building a resilient university: ensuring academic continuity - transition from face-to-face to online in the COVID-19 pandemic," where they present the challenges that academic institutions are facing while migrating to an online learning environment. These two papers reveal how digital technologies have made possible the impossible. Still, many questions remain open as to the achievement of SDG 4 on Quality Education. The survey run by International Association of Maritime Universities (IAMU) in 2020 showed that practical training is a major concern for all universities, and in particular the impact of the COVID-19 pandemic on recruitment (IAMU 2020).

\section{Digitization and maritime security}

The COVID-19 pandemic has forced the global community to seek and quickly implement meetings and transactions that would otherwise require physical presence. 
Classrooms and offices have switched over to live streaming solutions. Shoppers have abandoned in-person shopping for online purchases. Email and digital messaging applications have become even more important for instant communications. For the maritime industry, the COVID-19 pandemic has accelerated the use of digitization and automation, and the move from a physical to a virtual business environment brought on through cross-border ship-shore electronic exchange of information, electronic bills of lading, and the general expansion of the distributed ledger technology (World Economic Forum 2019-2020). In a similar vein, the STC is discussing electronic certificates and documents within the MLC, 2006's framework in line with IMO's developments in these matters. Flag States and recognized organizations have implemented remote monitoring and inspection solutions to minimize disruption in certification processes. While information and communication systems and technologies have been used as a way to increase the efficiency of operations (UNCTAD 2019b), the COVID19 pandemic has also made apparent that digitization and automation are no longer mere luxuries but rather necessities and the most viable options to keep maritime operations going.

Digitization does not only bring opportunities, but also risks and threats such as cyberattacks. In fact, the NotPetya malware attacks, one of the most devastating cyberattacks in history, featured a prominent stakeholder in the maritime industry. Maersk estimated a loss of USD 250 to 300 million when the Danish shipping company's critical systems were disrupted by the malware in June 2018. Unable to process shipping orders, the company's revenue stream was frozen for weeks (Allen $\mathrm{Sr}$ 2018). The maritime industry is particularly vulnerable and any attack will have obvious implications on global trade. The tight interconnection between ships, ports, cargo owners, and dozens of other stakeholders belie the fragmented approach that the maritime industry currently has to assessing cyber risks. Discussions around cybersecurity threats have been around for decades, but the need to develop rapid and concrete solutions has also been made more urgent by the accelerated shift to digitized systems because of the COVID-19 pandemic.

The above concerns are underscored by Manuela Bocayuva Carvalho in her paper "Cybersecurity in The European Union Port Sector in Light of the Digital Transformation and the Covid-19 Pandemic." The European Union Agency for Cybersecurity (ENISA) had already warned against the lack of awareness in EU governments, ports, and maritime businesses as to the critical threat that a cyberattack poses to their operation and, in general, a country's economy in 2011 and again in 2019. In June of 2020, the COVID-19 pandemic and the fact that only one-third of IMO members have functioning Port Community Systems (PCS) triggered a call for action to accelerate digitization in the maritime sector (International Association of Ports and Harbors (IAPH), BIMCO, the International Cargo Handling Coordination Association (ICHCA), the International Chamber of Shipping (ICS), the International Harbour Masters' Association (IHMA), the International Maritime Pilots Association (IMPA), the International Port Community Systems Association (IPCSA), the International Ship Suppliers' Association (ISSA), the Federation of National Associations of Ship Brokers and Agents (FONASBA) and the PROTECT Group, June 2020). Remarkably, this document also called for the review of the IMO's Guidelines on Maritime Cyber Risk Management, hence the timeliness of Ms. Carvalho's analysis 
on the legal framework to address cyber risks in the port environment and the urgency to move forward.

If the above paper highlights stakeholders' lack of awareness as regards to the significance of cybersecurity, Kristen Kuhn, Salih Bicakci, and Siraj Ahmed Shaikh's "COVID-19 Digitisation in Maritime: Understanding Cyber Risks" delves into the significance of understanding cyber risks by addressing stakeholders' cyber risk perception. Their article includes a case study surrounding a cybersecurity decisionmaking exercise conducted in 2020. The findings from the exercise not only demonstrate a strong link between cyber risk perception and cyber incident response, but also show that cyber risk perception can be improved significantly through iterative learning. The paper highlights how cybersecurity has become a governance factor in maritime and underscores the utmost importance of training, capacity-building, and joint response in any successful effort to address threats to cybersecurity.

\section{The socio-economic impact of COVID-19 pandemic in shipping and ports}

As a result of the health crisis, disruptions in the flow of goods, people, and services put a maritime sector that is facing significant business losses and bankruptcies because of the legal implications of the crisis, among other reasons, under enormous pressure. Governments reacted ahead of the expected recession establishing economic emergency and social protection measures, fine-tuning legislation and encouraging the resort to negotiation and alternative dispute resolution methods. Nevertheless, shipping, because of its global nature, has faced challenges in availing itself of these measures, while in other cases, competition issues arose as a result of market distortions created by State aid packages. More than one year after the outbreak of the COVID-19 pandemic, shipping is safely sailing towards recovery, although the cruise sector still remains largely inactive.

Nevertheless, the pandemic has brought opportunities to re-think maritime transport strategies as Adekola Oyenuga's article intends. "Perspectives on the impact of the COVID-19 pandemic on the global and African maritime transport sectors, and the potential implications for Africa's maritime governance" goes beyond the immediate effects to analyse how the pandemic has impacted five global trends that also concern the maritime transport sector, i.e., trade tensions, geopolitical developments, structural disruptions, regulatory pressures, and environmental incidents. Against this backdrop, enhancing maritime governance is critical in particular for the African Continent where the share of global container port traffic is at the moment negligible.

The spread of the COVID-19 disease led to the implementation of global restrictions and strict safety measures. Those restrictions had and are still having consequences for the whole transport sector, including the shipping and port sectors. During the pandemic, the shipping sector adjusted its capacity and ports took measures to maintain their business in response to the ship calls, coordinating the different actions and procedures while avoiding as much as possible disruption to world connectivity. Mohammad Samsul Mannan, Md. Mostafa Aziz Shaheen, and Rana Saha provide in "Covid-19: Chittagong Port and Aftermath" an overview of the said socio-economic impacts in Bangladesh. This provides a mirror for many other ports whose operation 
has been significantly affected in terms of port of call, warehouse and distribution activities, hinterland connections, and port employees. Interestingly, the paper also provides strategies for their mitigation that include further digitization and infrastructure development.

According to the European Sea Port Organization (ESPO), European ports have activated contingency plans to ensure that they remain fully operational during this crisis and this also highlights their important role as essential and critical infrastructures playing a crucial role in the supply of necessary goods. Equally important, the shipping and port sectors need to enhance multi-sectoral, regional, and global cooperation, collaboration, and coordination, while at the same time accelerating the integration of digital technologies in order to streamline the whole supply chain, and facilitate trade and efficient operations and, in turn, gain a better understanding of how to manage and use capacity.

A recovery strategy on how to overcome the economic crisis needs to include and strengthen the existing support, harmonization, and standardisation of efforts at national, regional, and global levels. It is also crucial that ports and transport infrastructure projects and investments can be pursued as planned in order to fulfil their critical and essential role in the supply chain and avoid disruption and strengthen connectivity. Therefore, recovery along with post COVID-19 priorities requires port policymakers and practitioners to concentrate on building risk business model-based plans for future similar events such as further pandemics, climate change impacts, political issues, natural disasters, cyber risks, and economic crises.

\section{Conclusion}

The six papers published in this issue are testament to the resilience of the maritime community and their creativity and adaptability while facing major challenges such as the ones brought to light by the COVID-19 pandemic. The discussion that they manage to engage with does not include, however, how to achieve an environmentally sustainable shipping industry. The silence might be telling, though, of what the priorities have been during these months. While the path to recovery has put this critical issue on the institutional and industry agenda once more, the pandemic has nevertheless shed light on the need to rethink and enhance maritime governance from a holistic and global approach; the world interconnection and their dependence on the global supply chain have been made more apparent than ever and, nevertheless, shipping has not been classified as an essential sector in a majority of countries. The social dimension of sustainability has suffered the most, but it might apply as well to the greening of the industry. Moreover, the repercussions of the pandemic sent warnings to all the relevant actors in preparing plans and increasing their resilience for future risks and disruptions as well as to ensure that shipping, ports, and terminals function well along the global supply chain. More research is needed to monitor negative consequences, focus on potential long-term impacts, and develop adaptation strategies. Finally, we cannot but concur with the appreciation that the COVID-19 pandemic has acted as magnifier and intensifier of existing problems, and hope that this issue moves to reflection of what has happened, and opens the door to better governance. 


\section{References}

Allen CH Sr (2018) Developing and implementing a maritime cybersecurity risk assessment model. Univ San Francisco Marit Law J 31(2):77-105

European Commission (2020) Communication from the Commission Guidelines on protection of health, repatriation and travel arrangements for seafarers, passengers and other persons on board ships, Brussels, $\mathrm{C}(2020) 3100$ final

IAMU (2020) Summary results of the survey on the impact of and response to COVID-19 by IAMU member universities. Available at: https://iamu-edu.org/summary-results-of-the-survey-on-the-impact-of-andresponse-to-covid-19-by-iamu-member-universities/ [last access: 6 May 2021]

IAPH-WPSP Port Economic Impact Barometer (2020) (Attributed Authors: Notteboom, T., Pallis, T.)

IMO (2020a) Circular Letter No.4204/Add.12 - Coronavirus (COVID 19) - EC Guidelines on protection of health, repatriation and travel arrangements for seafarers, passengers and other persons on board ships

IMO (2020b) Circular Letter No.4204/Add.14 - Coronavirus (COVID-19) - Recommended framework of protocols for ensuring safe ship crew changes and travel during the coronavirus (COVID-19) pandemic

IMO-ICAO-ILO (2020) Circular Letter No.4204/Add. 18 - Joint Statement IMO-ICAO-ILO on designation of seafarers, marine personnel, fishing vessel personnel, offshore energy sector personnel, aviation personnel, air cargo supply chain personnel and service provider personnel at airports and ports as key workers, and on facilitation of crew changes in ports and airports in the context of the COVID-19 pandemic

Micco A, Pizzolitto G, Sánchez R, Hoffmann J, Sgut M, Wilmsmeier G (2003) Port efficiency and international trade: port efficiency as a determinant of maritime transport costs. Marit Econ Logist 5(2): 199-218 UNCTAD (2017). Review of Maritime Transport 2017 (United Nations publication. Sales No. E.17.II.D.10. New York and Geneva)

Council of the European Union (2021) An international treaty on pandemic prevention and preparedness, available at: https://www.consilium.europa.eu/en/policies/coronavirus/pandemic-treaty/. Accessed 29 May 2021

International Association of Ports and Harbors (IAPH), BIMCO, the International Cargo Handling Coordination Association (ICHCA), the International Chamber of Shipping (ICS), the International Harbour Masters' Association (IHMA), the International Maritime Pilots Association (IMPA), the International Port Community Systems Association (IPCSA), the International Ship Suppliers' Association (ISSA), the Federation of National Associations of Ship Brokers and Agents (FONASBA) and the PROTECT Group (2020) Call for Accelerating Digitalisation of Maritime Trade and Logistics

See Article 2 of IHR 2005

See Part V of IHR 2005

Special Tripartite Committee of the MLC, 2006 (2021) Resolution concerning the implementation and practical application of the MLC, 2006 during the COVID-19 pandemic, available at https:/www.ilo.org/wcmsp5/groups/ public/@ed_norm/@normes/documents/genericdocument/wcms_782881.pdf (last access, 6 May 2021)

UNCTAD (2019a) Sustainable transport infrastructure in a world of growing trade and climate change, SDG [Sustainable Development Goal] pulse

UNCTAD (2019b) Digitalization in maritime transport: ensuring opportunities for development. Policy Brief No. 75. UNCTAD/PRESS/PB/2019/4

UNCTAD (2020) COVID-19: a 10-point action plan to strengthen international trade and facilitation in times of pandemic. No.79. Available at UNCTAD. https://unctad.org/en/PublicationsLipresspb2020d3_en.pdf/ presspb2020d3_en.pdf. Accessed 29 May 2021

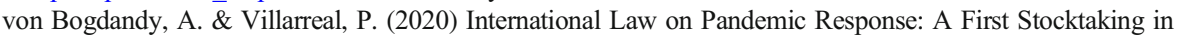 Light of the Coronavirus Crisis. Max Planck Institute for Comparative Public Law \& International Law (MPIL) Research Paper No. 2020-07, Available at SSRN: https://ssrn.com/abstract=3561650 or https:// doi.org/10.2139/ssrn.3561650

World Economic Forum (2019-2020) White paper on inclusive deployment of blockchain for supply chains. World Economic Forum

World Maritime University (2020) A culture of adjustment, evaluating the implementation of the current maritime regulatory framework on rest and work hours (EVREST). World Maritime University. (Attributed authors: Baumler, R., De Klerk, Y., Manuel, M.E., and Carballo Piñeiro, L.)

Publisher's note Springer Nature remains neutral with regard to jurisdictional claims in published maps and institutional affiliations. 